\title{
Design and Research on Intelligent Electronic Meters with Hand Tran- scribers
}

\author{
Chunfeng $\mathrm{Li}^{*}{ }^{*}$, , Dandan $\mathrm{Sun}^{2}$ and Xiang Zhang ${ }^{3}$ \\ ${ }^{I}$ Electronic Information Engineering College of Changchun University, Changchun, 130022, China \\ ${ }^{2}$ Foreign Language College of Changchun University, Changchun, 130022, China \\ ${ }^{3}$ Mechanical and Vehicle Engineering College of Changchun University, Changchun, 130022, China
}

\begin{abstract}
The essay first establishes the general design scheme about software and hardware circuits of intelligent electronic meters with hand transcribers and elects the more advanced RN8209G multifunctional, anti-stealing, monophrase measurement chip as the energy measurement chip; then designs the main program flow chart of hardware and software in the systematic design scheme, such as the energy measurement chip, the current sample circuit, the voltage sample circuit, and hand transcriber, etc.
\end{abstract}

Keywords: Single chip AT89S52, electronic meter, hand transcriber.

\section{INTRODUCTION}

In recent years, our country introduces a serial of policies to promote the development of the urban-rural integration. As the result urban population increase, real estate thrives and new residential quarters spring up. At the same time, with the continuous development of computer, microelectronic technique and power automation, the scale of power sale market constantly expands, the number of users unceasingly increase, traditional meter-reading cannot satisfy the requirement of power companies to the present management model. So in order to make the power consumption mode of residents more regularization, more rationalization and higher efficiency, it is necessary to reform the traditional meter reading mode to satisfy the speedy development of economy and society in our country. For this purpose, the essay proposes the design and research of intelligent electronic meters with hand transcribers. The research takes GPRS service platform of Mobile Corporation as basis to construct the new remote meter-reading system and achieve remote, real-time and automatic meter-reading. Simultaneously considering signals in remote mountainous are not good, the essay designs hand transcribers of infrared communication meterreading to copy meters.

\section{GENERAL DESIGN SCHEME}

The general design scheme of intelligent electronic meters with hand transcribers is shown as Fig. (1). The design scheme takes single chip AT89S52 as the core to design voltage/current sample circuits, voltage/current transforms, clock circuits, energy measurement chips, memory cell EEPROM, display units, infrared receiving circuits, infrared transmission circuits and power units, etc. GPRS adopts the M590 module produced by Shenzhen Youfang Science and Technology Ltd which has universally certificated GPRS R4 agreement and the function of sending message and data, and serial port CMUX; the energy measurement chip adopts model RN8209G, a kind of multifunctional anti-stealing monophrase measurement chip produced in china, to make sure the accuracy of energy measurement; $\mathrm{MCU}$ is the core part of the design, it chooses the low power consumption single chip specified single chip AT 89S52 as the main controller to make the operation of system reliable; RS485 can achieve the function of network communication, it is mainly used in local communication in this design. In the design, infrared receiving and transmission circuits are mainly used in remote mountainous areas where the signals are not good to realize infrared receiving. In order to display and watch conveniently, the design adopts LCD to show operational state, quantities of electricity in electronic meters and fault message in real time.

\section{DESIGN SCHEME OF HARDWARE CIRCUIT}

\subsection{Energy Measurement Chip}

The function of energy measurement chip RN8209Gis shown as Fig. (2). The multifunctional anti-stealing monophase energy measurement chip RN8209G is the measurement chip that has two-way measurement which especially supports direct current measurement, and has 2 serial SPI/UART communication interface. The error of active energy is in 5000:1, dynamic range is less than $1 \%$, supply power voltage is $5 \mathrm{v}$ and has the function of anti-stealing. 


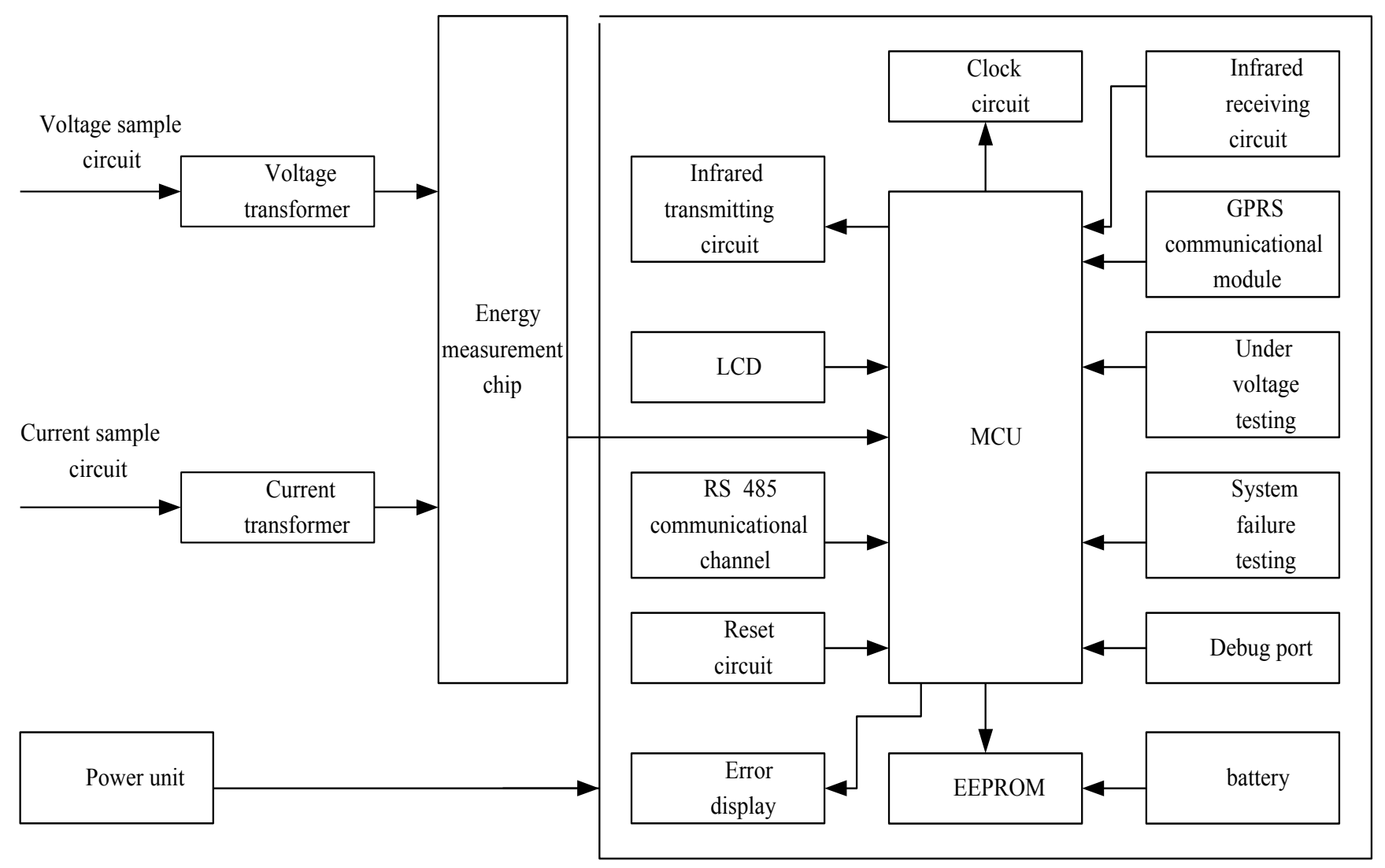

Fig. (1). General design scheme.

It supports the whole digital gain, phase and offset correction. Pin PF out puts active energy impulse, pin OF outputs custom energy impulse frequency.

\subsection{Current/Voltage Sample Circuits}

The current/voltage sample circuits designed in the essay is shown as Fig. (3). The current sample circuit adopts differential input mode, the outlet ends separately connect with energy measurement chip VIP and VIN. The voltage sample circuit adopts resister string mode, the outlet ends separately connect with energy measurement chip V2P and V2N.

\subsection{Infrared Transmitting and Receiving Circuit}

The infrared transmitting and receiving circuit is shown as Fig. (4). The designed infrared transmitting circuit of electronic meters and hand transcriber in the essay adopts time base circuit NE555. The output pins of time base circuit NE555 generate carrier signals to drive infrared LED to glow. Because the power of infrared impulse transmitted by one infrared LED is smaller, the essay adopts two paralleling infrared LED tubes to increase the range of infrared emanation. The infrared impulse emitted by the infrared transmitting circuit is received by infrared optical sensor of infrared receiving circuit. But because the receiving signals are optical signals, it needs to turn optical signals into electrical signals and then enlarge electrical signals. The component that combines photoelectric transducer, amplifier and regulating circuit together is infrared IRM; the supply voltage is $4.5 \mathrm{~V}$ to $5.5 \mathrm{~V}$.

\subsection{General Design Scheme of Hand Transcribers}

The general design scheme of hand transcribers is shown as Fig. (5). It takes microcontroller AT89S5 as the core to design the periphery supply circuit, the touch screen, the calendar/clock chip, the printer interface, the infrared transmitting circuit, the infrared receiving circuit and RS 485 interface, etc. Among them, the infrared transmitting circuit and the infrared receiving circuit are the same as the infrared receiving and transmitting circuit of electronic meters. The design scheme can realize to infrared receive and transmit data of electronic meters.

\section{DESIGN SCHEME OF SOFTWARE}

The design scheme of software is shown as Fig. (6). The design employs module design scheme and mainly takes GPRS remote meter-reading system as foundation, simultaneously designs to use infrared transmitting and receiving hand transcribers to realize the intellectual meter-reading in remote mountainous areas which have no GPRS communicational signals, and to define mutual coordinate relations, when there is no GPRS communicational signals, the infrared meterreading mode will be switched to automatically, first addresses of electronic meters are sent, then sending and receiving subroutines are called to realize the infrared meter-reading. 


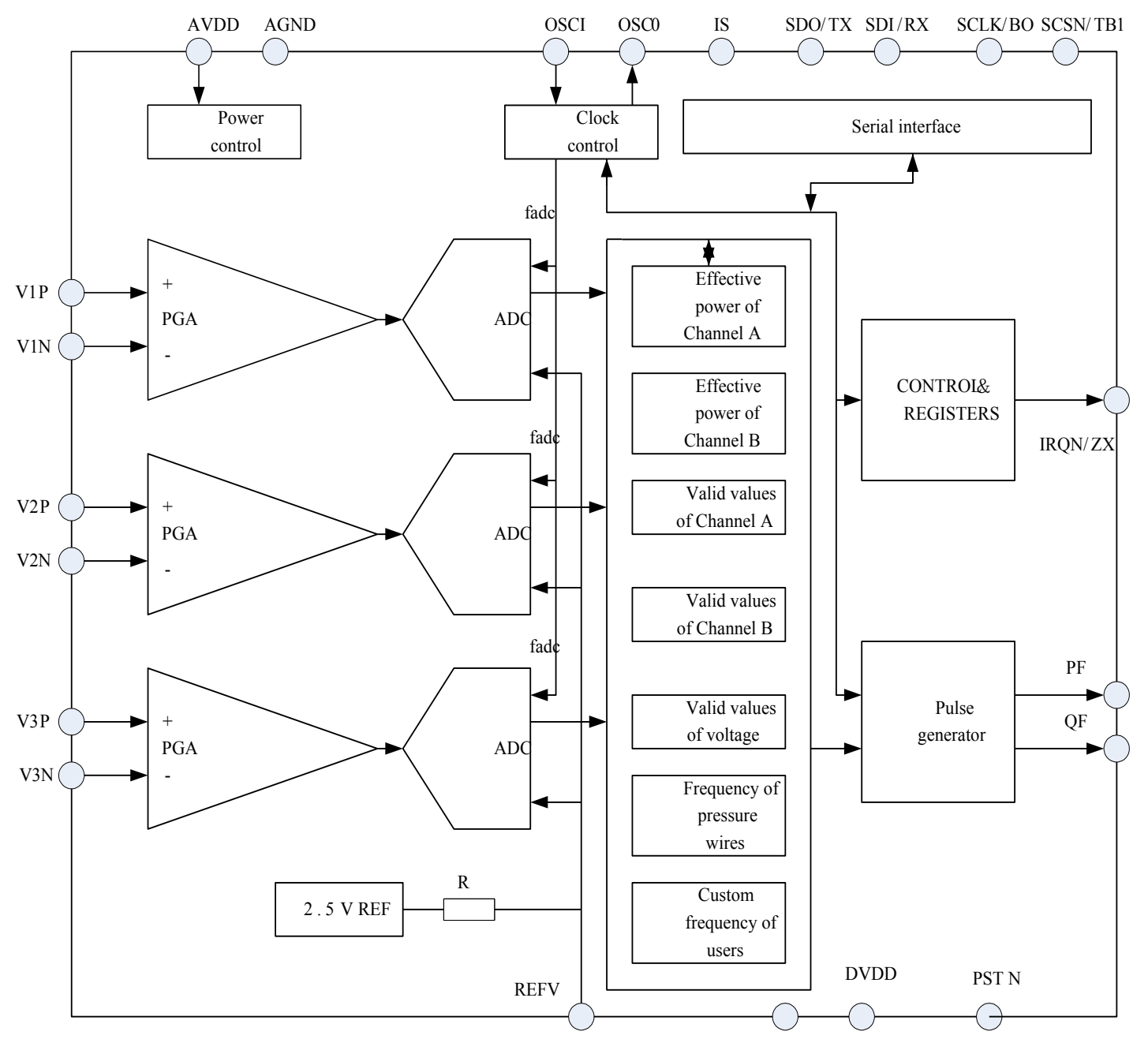

Fig. (2). Functional diagram of chip RN8209G.

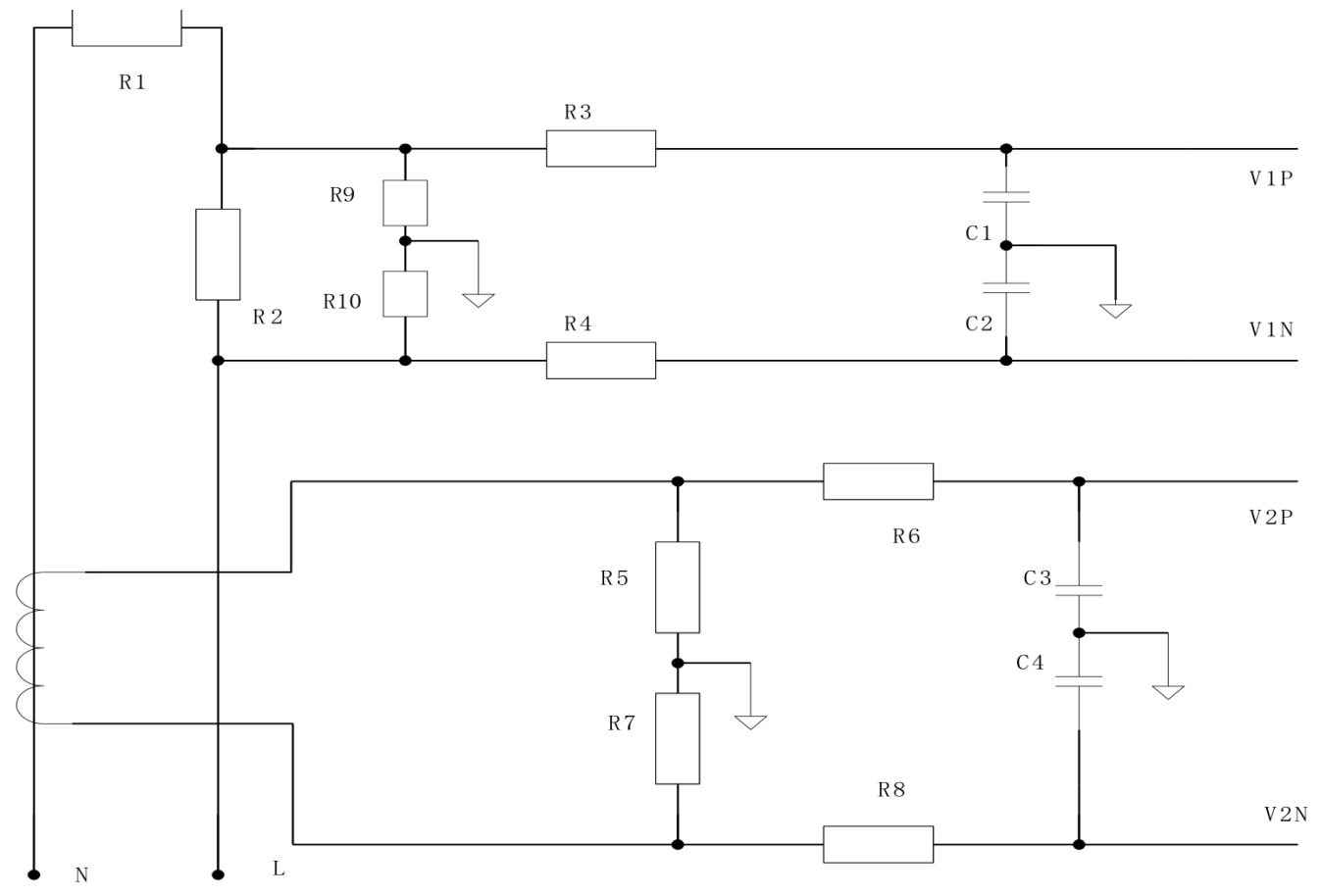

Fig. (3). Voltage/ Current sample circuits. 


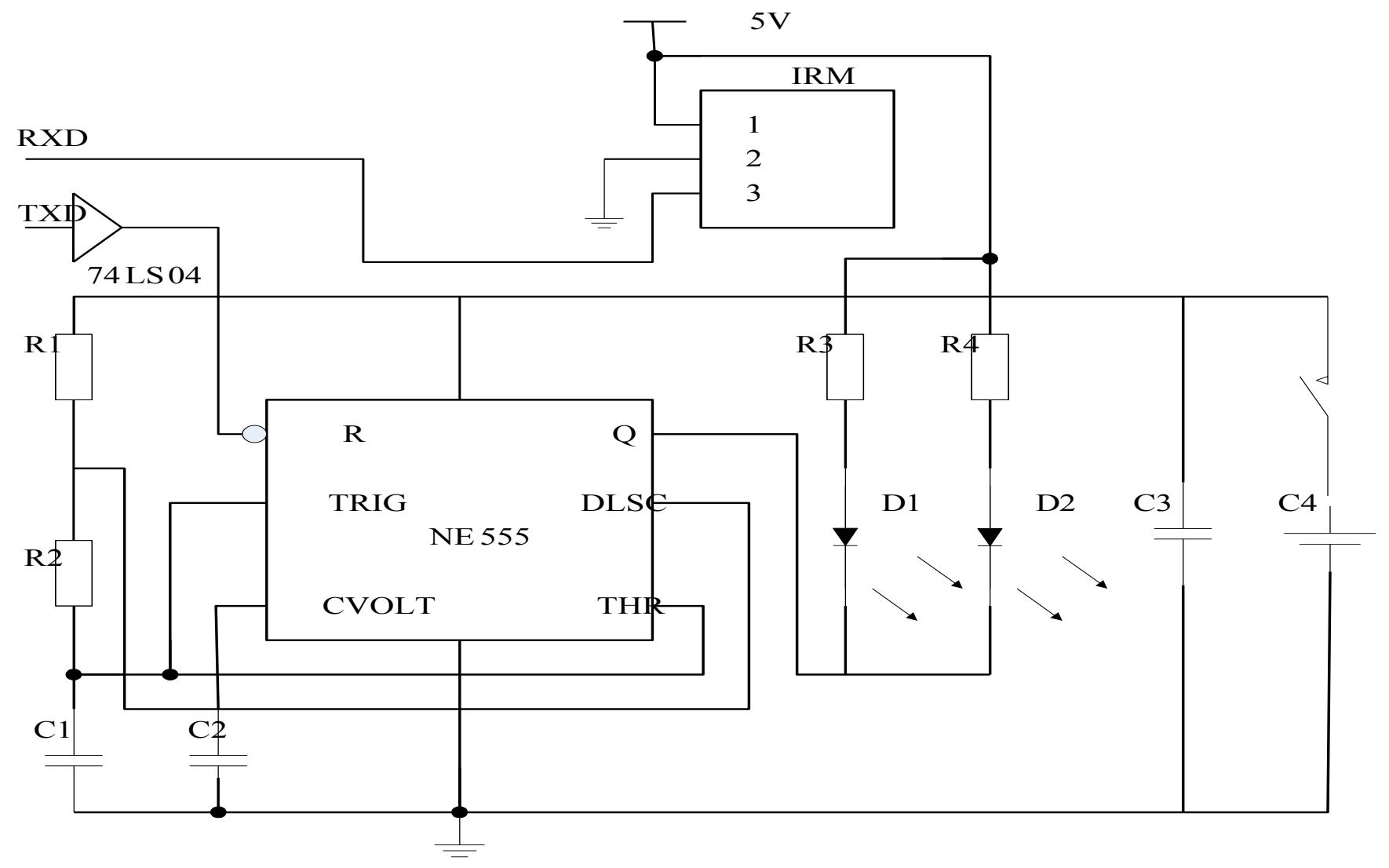

Fig. (4). Infrared transmitting and receiving circuit.

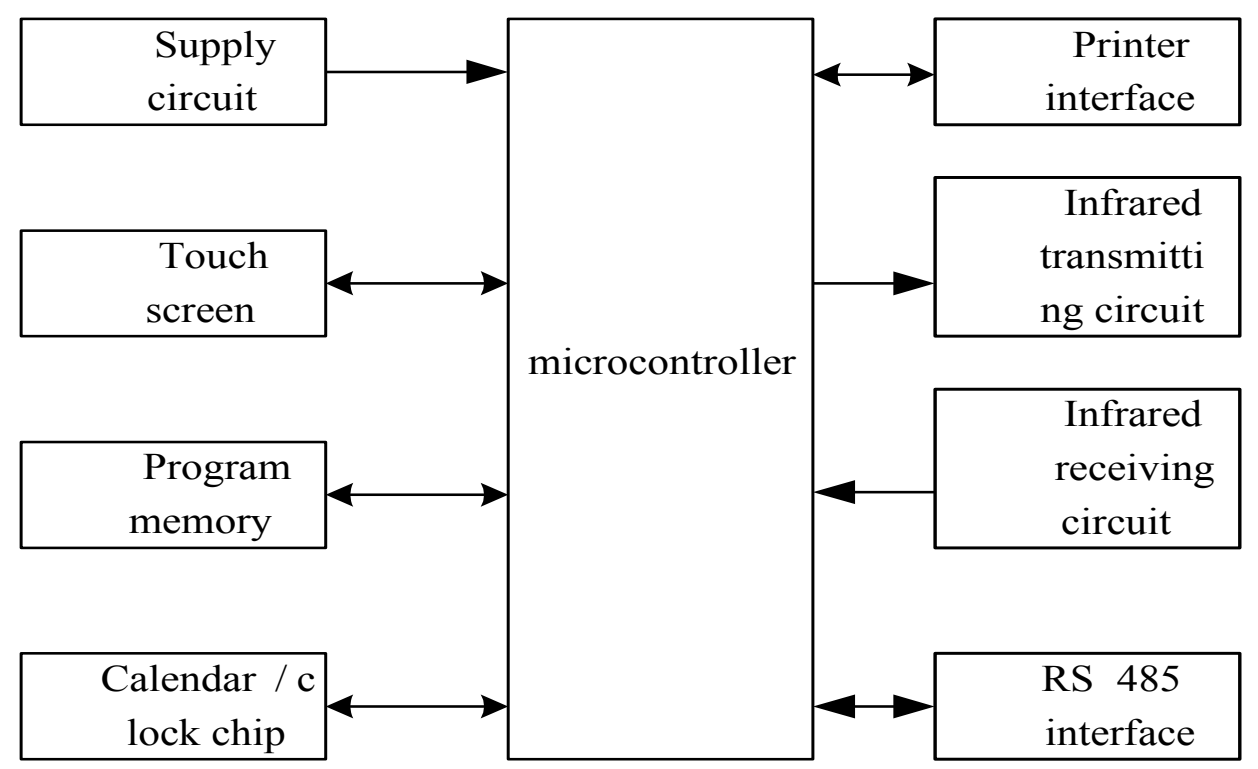

Fig. (5). General design scheme of hand transcribers. 


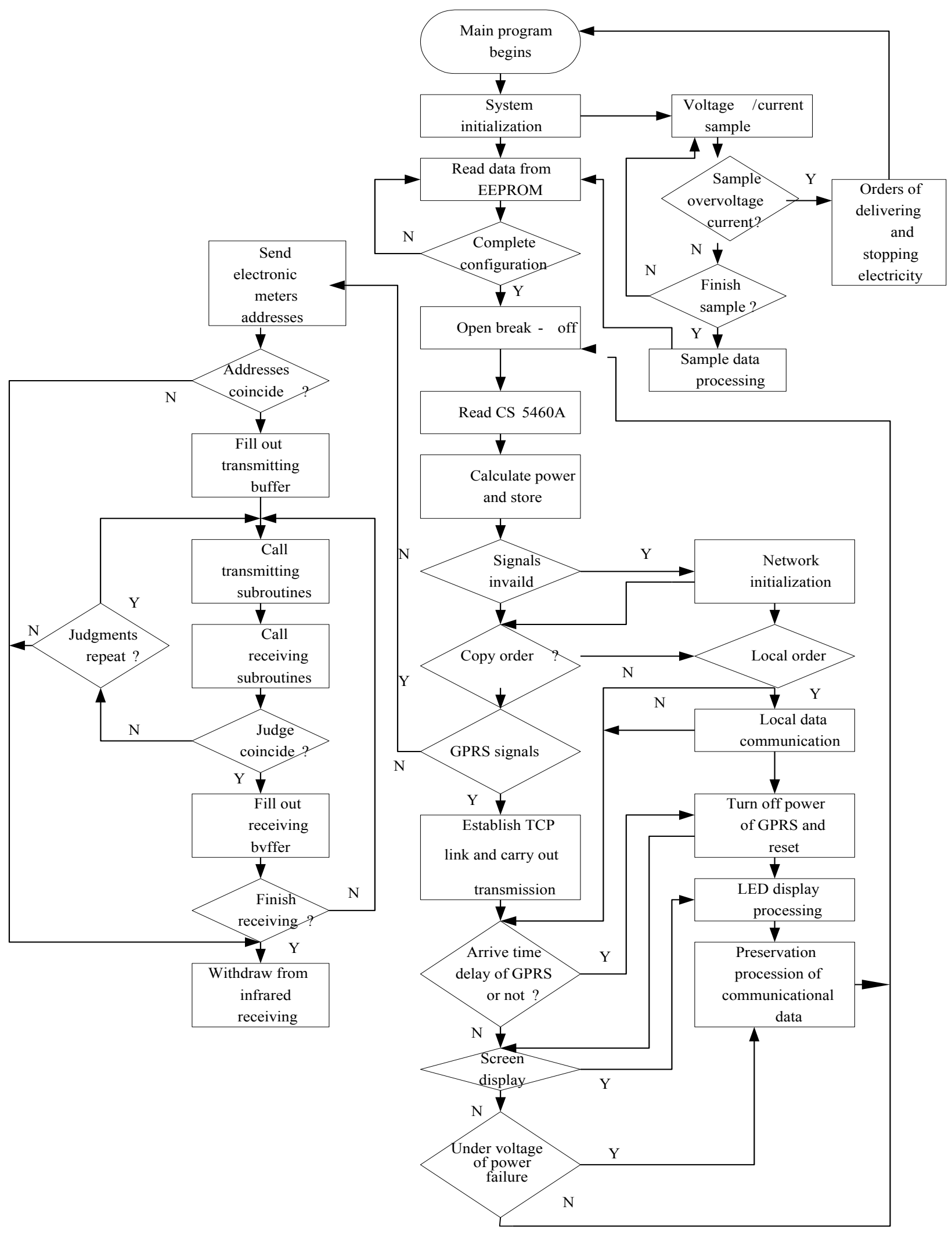

Fig. (6). Design scheme of software.

\section{CONCLUSION}

Through the design and research on intelligent electronic meters with hand transcribers, the essay designed the scheme of energy measurement chips, voltage/current circuits, infrared transmitting and receiving circuits, hand transcribers, and designed the main program flowing chart of software parts, which supply theoretical supports for further researchers. 


\section{CONFLICT OF INTEREST}

The author confirms that this article content has no conflict of interest.

\section{ACKNOWLEDGEMENTS}

During the process of writing the essay, some teachers in Electronic information engineering college of Changchun University have give me great support, here give my sincere thanks to them.

\section{REFERENCES}

[1] "RN 8209G multifunctional, anti- stealing electricity, single phase metering chip", [Online] http://www.ireaderopto.com/Products/rn8209gdgn.html
[2] F. Z. Hao, "Design and application of GPRS remote multifunctional electric meters," Jiangxi Electric Power, vol.35, no.4, pp.21-25, 2011.

[3] K. S. Jiang, "Application Practice of GPRS Remote Meter-reading System," China Power Press, Beijing, 2007.

[4] Y. C. Jiang, "Research and development of intelligent electric meters," Northwestern polytechnic University, 2002.

[5] R. Z. Zhang, and B. D. Qu, "Design of three-phase precisely measuring intelligent electronic meters," Electronic Measurement Technology, vol.31, no.9, pp.150-153, 2008.

[6] L. Li and Z. Z. Ren, "Wireless communication module design of intelligent meters based on GPRS," Journals of Shenyang Institute of Chemical Technology, January, 2007.

Received: February 18, 2015

Revised: March 22, 2015

Accepted: March 31, 2015

(C) Li et al.; Licensee Bentham Open.

This is an open access article licensed under the terms of the Creative Commons Attribution Non-Commercial License (http://creativecommons.org/licenses/by$\mathrm{nc} / 3.0 /$ ) which permits unrestricted, non-commercial use, distribution and reproduction in any medium, provided the work is properly cited. 